\title{
Validity and reliability study of the Turkish version of SACRAH (Score for Assessment and quantification of Chronic Rheumatic Affections of the Hands)
}

\author{
N.G. Tore ${ }^{1}$, F. Sari', Z. Tuna', O. Varan², H. Babaoglu², B. Goker', D. Oskay ${ }^{1}$ \\ ${ }^{1}$ Department of Physiotherapy and Rehabilitation, Faculty of Health Sciences, Gazi University, Ankara, Turkey; \\ 2Division of Rheumatology, Department of Internal Medicine, Faculty of Medicine, Gazi University, \\ Ankara, Turkey
}

\begin{abstract}
SUMMARY
Rheumatic diseases cause deformities in the hands and affect daily living activities. Therefore, assessment of hand disabilities is important in rheumatic disease. The aim of this study was to test the validity and reliability of the Turkish version of the A Score For Assessment and Quantification of Chronic Rheumatic Affections of the Hands (SACRAH).

A translation and back-translation of the SACRAH were performed, according to the Beaton guidelines. Patients who were between 18-65 years old, who were literate in Turkish, who had rheumatic disease diagnosis and whose hands were affected, were included in the study. Patients who were using a splint during daytime were excluded from the study. They completed the Turkish version of Disabilities of the Arm, Shoulder and Hand Questionnaire (DASH-T) once and the final version of the SACRAH Questionnaire twice with a 7 days' interval. The internal consistency (Cronbach's $\alpha$ ) and reliability (test-retest reliability) of the questionnaire were assessed. Besides, correlations between SACRAH and DASH-T scores were analyzed using the Spearman correlation coefficient.

One hundred and twenty patients participated in the study. The Turkish version of the SACRAH met set criteria of reliability and validity. Internal consistency was excellent (Cronbach's $\alpha=0.88$ ) and test-retest reliability were very good $(\mathrm{r}=0.73)$. SACRAH showed a positive and statistically significant correlation with DASH-T scores $(\mathrm{r}=0.83, \mathrm{p}<0.001)$.

Our results show that the Turkish version of the SACRAH has excellent test-retest reliability and validity. As a result of this study we determined that SACRAH is a valid and reliable instrument for assessing functional status and subjective manual function in Turkish-speaking patients.
\end{abstract}

Key words: Hand; SACRAH; questionnaire; reliability; validity.

\section{INTRODUCTION}

$\mathrm{H}$ and deformity is frequently found in patients with rheumatic diseases. It leads to pain and loss of function (1). Deformities are often associated with reduced range of motion and grip strength. They have a great impact on hand functions and the ability to perform daily-life activities, leading to lower quality of life. Therefore, detailed inclusive evaluation of the hand is crucial in planning of therapeutic managements in these patients.

In practice, comprehensive clinical assessments of the hands are difficult and ortho- pedic outcome measurements are often focused on objective parameters such as clinical tests or radiographic analysis (2). However, they do not assess subjective parameters. For this purpose, different questionnaires and scales have been developed and validated to provide a comprehensive evaluation of stiffness, pain and the impact of the symptoms on daily life activities from a patients' perspective (3). These reflect subjective results (4). Moreover, since they take less time and are more practical, their usage is increasing, especially in clinical trials (5).

There are several questionnaires which 
evaluate hand functions, such as Cochin (6), ABILHAND (7), AUSCAN (8), Michigan Hand Outcomes (9) and DASH (10), which also evaluates the function of the shoulder and elbow and has been developed for patients with several pathologies of the hand. However, most of these questionnaires are developed in English speaking countries (11). In order to be used in different cultural settings and different languages, questionnaires should not only be translated but also adapted to the new cultural settings. The cross-cultural adaptation guidelines that were described by Beaton et al. are widely accepted and used for the translation and cultural adaptation of questionnaires (12).

A Score for Assessment and quantification of Chronic Rheumatic Affections of the Hands (SACRAH) was created to assess functional status and subjective manual function in patients who suffer from osteoarthritic or rheumatoid disease of the finger joints (13). During the creation process, Leeb et al. tried to choose questions that are related to hand functions. Questions which were based on the problems frequently reported by patients were selected. SACRAH consists of 23 questions and three categories which aim to determine the situation of the patients with rheumatic affections of the hands. The completion of SACRAH is easy and takes short time (13). All the features highlighted above provide advantages to this questionnaire in assessing hand functions in all rheumatic diseases.

The aim of this study was to test the reliability and validity of the SACRAH questionnaire among Turkish people and to carry out the cross-cultural adaptation.

\section{MATERIALS AND METHODS}

\section{Translation procedure}

The translation of the English version of the SACRAH into Turkish was done according to the forward-backward translation guidelines which were originally proposed by Beaton et al. (12) Forward translation from English into Turkish was done by two independent native Turkish speakers with different job profiles; one of them was a physiotherapist (informed translator) the other one was an English linguistic scientist (uninformed translator). The translators were fully competent in both languages. The translations received were discussed by them in a first consensus panel to obtain the first preliminary Turkish version. Back translation of the consensus Turkish version of SACRAH was done by two independent professional bilingual translators. The formation of the pre-final Turkish version of SACRAH was based on discussions in the second consensus panel within an expert committee composed of four translators, one Turkish linguist and one methodologist. Finally, the comprehensibility of the pre-final version of the SACRAH was tested on a heterogeneous group of 40 people (20 patients and 20 healthy people). They were asked whether they fully understood all of the questions or whether they had problems with the formulation.

\section{Patients}

The sample size was based upon the rule of 5 to 7 patients per question (14). The sample consisted of 120 patients ( 97 female, 23 male; mean age $53.38 \pm 11.23$; range: 18 to $65)$ with osteoarthritis, rheumatoid arthritis and scleroderma (diagnosis validated by a physician). Patients were referred to the outpatient department of physiotherapy and rehabilitation at Gazi University, Faculty of Health Sciences. The study was conducted between August 2016 and July 2017.

The inclusion criteria were:

1) diagnosis with the above rheumatologic diseases;

2) literacy in Turkish;

3) age between 18-65 years;

4) rheumatic disease with hand involvement;

5) receiving no new treatment between test-retest assessments.

The only exclusion criterion was use of a splint during day time. Signed informed consent was obtained from all participants. This study was done considering human rights and the study was approved by the Ethics Committee of Gazi University Health Sciences Institute. 


\section{Assessment of reliability and validity}

During the first assessment in the outpatient department of physiotherapy and rehabilitation at Gazi University, Faculty of Health Sciences, all participants completed the Turkish version of the SACRAH and DASH questionnaires. The SACRAH questionnaire was applied twice, 7 days apart, to assess test-retest reliability. The DASH questionnaire was applied to test the construct validity of SACRAH questionnaire.

The primary aim of SACRAH is to determine the condition of the hands of patients with rheumatic diseases. It was developed by B.F. Leeb et al. in 2003. It involves 23 VAS $(100 \mathrm{~mm})$ covering three different categories: functional impairment (17 items), stiffness (2 items) and pain (4 items). The first 17 questions inquire about hand functions. In this part, the daily living activities can be assessed using a range from " $(0)$ possible without any difficulty" to "(100) impossible". The following 2 questions inquire about stiffness. In this part, stiffness can be evaluated using a range from "(0) no stiffness" to "(100) unbearable stiffness". The last 4 questions inquire about pain. In this part, pain can be assessed using a range from "(0) no pain" to "(100) unbearable pain". SACRAH has been validated in patients with hand osteoarthritis and rheumatoid arthritis (13).

The DASH questionnaire is a region specific and self-administered questionnaire which evaluates, according to patients' perception, impairments, activity limitations and participation restriction for leisure activities and work. It was developed by the American Academy of Orthopedic Surgeons and Institute for Work and Health. DASH consists of 30 items. All the items have five response choices ranging from "no difficulty or no symptoms" to "unable to perform activity or severe symptoms". Twenty-one items include questions about the degree of difficulty in performing different types of physical activities, 6 items inquire about symptoms and the last 3 items inquire about the psychosocial effects. Moreover, DASH has two optional 4-item question sets which are named DASH sport/music (DASH-SM) and DASH work (DASH-W). DASH produces scores between 0 and 100. A high DASH score indicates severe disability. It takes nearly 10 minutes to complete the DASH questionnaire. DASH is available now in many languages and is being validated for validity and reliability (10). A Turkish version and cross-cultural adaptation of DASH was made by Duger et al. (15).

\section{Statistical analysis}

Statistical analysis of the data was performed using the Statistical Package for the Social Sciences (SPSS), version 22.0 (IBM). Statistical data were reported as mean \pm standard deviation $(\mathrm{X} \pm \mathrm{SD})$, median or percent $(\%)$. The Single Sample Kolmogorov Smirnov test was used to assess distribution of the data. For the purpose of determining the reliability of the SACRAH, test-retest and internal consistency analyses were conducted. The data were not normally distributed; subsequently, test-retest reliability was analyzed using Spearman's $\rho$ correlation coefficients. Cronbach's alpha was used to assess internal consistency. On this scale, 0.70 was considered significant (16). The construct validity of SACRAH was assessed by correlating total scores of SACRAH and DASH by using Spearman's $\rho$ correlation coefficients. Spearman $\rho$ correlation coefficients ranging between 0.81 and 1.00 were considered excellent, while 0.61 and $0.80,0.41$ and $0.60,0.21$ and 0.40 and 0 and 0.20 were accepted as very good, good, weak and bad, respectively (17). Statistical significance was accepted as $\mathrm{p}<0.05$.

\section{RESULTS}

\section{Patients' characteristics}

One hundred and nine of the 120 patients were right handed. Participants had various

Table I - Diagnosis of participants by number and percent.

\begin{tabular}{|l|c|c|}
\hline Primary diagnosis & $\mathbf{n}$ & $\%$ \\
\hline Rheumatoid arthritis & 80 & 66.7 \\
\hline Osteoarthritis & 20 & 16.7 \\
\hline Scleroderma & 20 & 16.7 \\
\hline
\end{tabular}


hand complaints related to their rheumatic diseases, including rheumatoid arthritis, osteoarthritis and scleroderma. Primary diagnoses of participants are shown in Table I. Descriptive statistics for the SACRAH and DASH scores received during patients' first and second visits are summarized in Table II.

\section{Reliability and validity}

Reliability was analysed according to internal consistency and determined using Cronbach's alpha coefficient. Internal consistency was high for the 23 questions in SACRAH (Cronbach's alpha coefficient was 0.889). Moreover, when Cronbach's alpha was calculated for each of the 23 questions through eliminating each question one by one, the range was found to be between 0.876-0.894. It was also found that none of the questions changed the internal consistency of SACRAH. The Cronbach alpha value if the item was excluded and the total value of Cronbach's alpha coefficient of the SACRAH are shown in Table III.

In order to assess the test-retest reliability, all participants completed the SACRAH again seven days later.

There was no statistically significant difference between test and retest scores of SACRAH [median score (IQR): 955 (8701070) versus 930 (850-1047.5)]. (Spearman's $\rho$ correlation coefficient was 0.737 , $\mathrm{p}<0.001$ ) (Table IV).

The high level of correlation we have demonstrated suggests that SACRAH has very good test-retest reliability.

For the construct validity, correlation analyses between SACRAH and DASH scores were performed. The SACRAH demonstrated significant and excellent correlation with DASH (Spearman's $\rho$ correlation coefficient, 0.83, $\mathrm{p}<0.001$ ) (Table V).

\section{DISCUSSION}

Questionnaires developed to assess hand function and disease activity need to be easily applicable, sensitive to changes, reproducible and should reflect the patients' actual situation according to their percep-
Table II - The median, Interquartile range (IQR), minimum and maximum scores of the SACRAH and DASH Questionnaires.*

\begin{tabular}{|l|c|c|}
\hline Instrument Scale & M (IQR) & Min-Max \\
\hline SACRAH (1 ${ }^{\text {st }}$ interview), $\mathrm{n}=120$ & $955(870-1070)$ & $340-1430$ \\
\hline SACRAH (2 ${ }^{\text {nd }}$ interview), $\mathrm{n}=120$ & $930(850-1047,5)$ & $210-1860$ \\
\hline DASH, $\mathrm{n}=120$ & $26.69(19.04-37.06)$ & $9.16-58.33$ \\
\hline
\end{tabular}

*SACRAH score, sum of $\mathrm{n}$ responses; DASH score, sum of $\mathrm{n}$ responses $/ \mathrm{n} \times 25$; $\mathrm{n}$, number of completed responses; Min, Minimum, Max, Maximum.

Table III - Cronbach's alpha coefficient for each item.

\begin{tabular}{|c|c|}
\hline Questions & $\begin{array}{l}\text { Cronbach's } \\
\text { alpha coefficient } \\
\text { for each item }\end{array}$ \\
\hline How difficult was it for you to unlock your door with a key & 0.876 \\
\hline How difficult was it for you to turn the door - or window - handle & 0.877 \\
\hline How difficult was it for you to fasten your bra/tie your tie & 0.879 \\
\hline $\begin{array}{l}\text { How difficult was it for you to button up and unbutton your } \\
\text { shirt/blouse }\end{array}$ & 0.880 \\
\hline How difficult was it for you to turn the tap & 0.878 \\
\hline How difficult was it for you to do up or undo a zip & 0.877 \\
\hline How difficult was it for you to tie your shoelaces & 0.878 \\
\hline How difficult was it for you to unscrew the toothpaste-cap & 0.886 \\
\hline How difficult was it for you to strike a match & 0.884 \\
\hline How difficult was it for you to hold a mug & 0.883 \\
\hline How difficult was it for you to buckle up your belt & 0.882 \\
\hline How difficult was it for you to cut and file your fingernails & 0.883 \\
\hline How difficult was it for you to turn the ignition key in your car & 0.886 \\
\hline How difficult was it for you to turn the pages of the newspaper & 0.883 \\
\hline How difficult was it for you to handle paper money & 0.885 \\
\hline How difficult was it for you to write & 0.892 \\
\hline How difficult was it for you to cut with a kitchen knife & 0.889 \\
\hline $\begin{array}{l}\text { How severe was your joint stiffness immediately after waking } \\
\text { up first thing in the morning? }\end{array}$ & 0.894 \\
\hline $\begin{array}{l}\text { How severe was your joint stiffness later in the day, after a } \\
\text { period of resting time? }\end{array}$ & 0.889 \\
\hline How severe was your pain during regular daily work? & 0.891 \\
\hline How severe was your pain during intensive work? & 0.890 \\
\hline How severe was your pain at times of inactivity? & 0.890 \\
\hline How severe was your pain during the night? & 0.893 \\
\hline Total & 0.889 \\
\hline
\end{tabular}

Table IV - Test-retest reliability of the SACRAH questionnaire.

\begin{tabular}{|l|c|c|}
\hline \multicolumn{3}{|c|}{$\begin{array}{c}\text { SACRAH } \\
\text { Second visit }\end{array}$} \\
\hline SACRAH & $\begin{array}{c}\text { Spearman's Correlation } \\
\text { Significance }\end{array}$ & 0.737 \\
First visit & $<0.001$ \\
\hline
\end{tabular}


Table V - Correlation value of SACRAH and DASH questionnaires.

\begin{tabular}{|l|c|c|}
\hline \multicolumn{3}{|c|}{ DASH } \\
\hline SACRAH & $r$ & $p$ \\
& 0.83 & $<0.001$ \\
\hline
\end{tabular}

tion (17). Many self-reported questionnaires have been developed which can be used additionally to provide more comprehensive evaluation of the patients' status. SACRAH is one of the patient-reported measurements, originally consisting of 23 easy-to-complete questions, and it aims to determine the condition of the hands of patients with rheumatic disease. The SACRAH questions are separated into 3 subscales: functional impairment, stiffness and pain (13).

In this study, we present the validation process of the cross-cultural adaptation of the SACRAH to the Turkish language and demonstrated reliability and validity of SACRAH in Turkish patients with rheumatic diseases.

The Turkish translation and cultural adaptation of SACRAH was performed following a systematic standardized approach. In doing this, we did not encounter any discrepancy because of cultural or linguistic differences.

The validation of SACRAH was initially demonstrated by Leeb et al. by comparing SACRAH scores with physicians' global assessments (13). In our study, the correlation between SACRAH and DASH scores was analyzed to assess the construct validity of SACRAH, with a Spearman's $\rho=0.83$, indicating an excellent correlation between the SACRAH and DASH Questionnaires. To ensure the test-retest reliability of SAC$\mathrm{RAH}$, the recommended time period between repeated questionnaires is between 2 days and 2 weeks (18). In this study, the time interval for the test and retest of SACRAH was 1 week.

In the current study, the test-retest reliability of the Turkish version of SACRAH was determined to be high. The reliability of the Turkish version was tested with a one week interval because the symptoms did not show dramatic changes. The Spear- man's $\rho$ correlation coefficient was 0.737 , revealing very good reliability. The very good test-retest reliability suggests the stability of SACRAH over time and the consistency of the total scores between 2 assessments.

When investigating the reliability of a questionnaire, Cronbach's alpha is a useful indicator and thus demonstrates the precision of the questionnaire studied. In our study, internal consistency of the subscales was analyzed by taking into consideration the value of Cronbach's alpha. Cronbach's alpha coefficient was excellent with results ranging from 0.876-0.894. Overall, internal consistency was also very high, with a score of 0.889 . In the literature the recommended internal consistency of a questionnaire ranges between 0.7 and 0.95 (16). Thus, the questionnaire is indeed appropriate for the population of this study. Having Cronbach's alpha coefficient value lower than 0.95 confirms that there was no item redundancy. Excellent internal consistency in multidimensional questionnaires indicates that the questions in different dimensions are strongly correlated.

\section{CONCLUSIONS}

Translation and cross-cultural adaptation of questionnaires would allow comparisons between different nations and allow exchange of information (11). SACRAH was translated into Turkish to confirm its validity and reliability. In this study it has been demonstrated that the Turkish version of the SACRAH is reliable and valid in patients with RA, OA and SSc. The limitation of this study is that responsiveness analysis was not conducted. Validity studies of SACRAH for other rheumatic diseases are also needed. Future studies should focus on this topic and also the responsiveness of SACRAH.

Contributions: the authors contributed equally.

Conflict of interests: the authors declare no potential conflict of interests. 


\section{REFERENCES}

1. Reyes RA, Lopez COL, Hernandez EA, et al. Evaluation of hand function in rheumatic disease. Validation and usefulness of the Spanish Version AUSCAN, m-SACRAH, and Cochin Questionnaires. Reumatol Clin. 2012; 8: 250-4.

2. Padua R, Padua L, Ceccarelli E, et al. Italian version of the Disability of the Arm, Shoulder and Hand (DASH) questionnaire. Cross-cultural adaptation and validation. J Hand Surg. 2003; 28: 179-86.

3. Beaton DE, Richards RR. Measuring function of the shoulder. A cross-sectional comparison of five questionnaires. JBJS 1996; 78: 882-90.

4. Kotsis SV, Lau FH, Chung KC. Responsiveness of the Michigan Hand Outcomes Questionnaire and physical measurements in outcome studies of distal radius fracture treatment. J Hand. 2007; 32: 84-90.

5. Kurimoto S, Yamamoto M, Shinohara T, et al. Favorable effects of explanatory illustrations attached to a self-administered questionnaire for upper extremity disorders. Qual Life Res. 2013; 22: 1145-49.

6. Duruoz M, Poiraudeau S, Fermanian J, et al. Development and validation of a rheumatoid hand functional disability scale that assesses functional handicap. J Rheumatol. 1996; 23: 1167-72.

7. Penta M, Thonnard JL, Tesio L. ABILHAND: a Rasch-built measure of manual ability. Archiv Phys Med Rehab. 1998; 79: 1038-42.

8. Bellamy N, Campbell J, Haraoui B, et al. Dimensionality and clinical importance of pain and disability in hand osteoarthritis: development of the Australian/Canadian (AUSCAN) Osteoarthritis Hand Index. Osteoarthr Cartilage. 2002; 10: 855-62.

9. Chung KC, Pillsbury MS, Walters MR, et al. Reliability and validity testing of the Michi- gan Hand Outcomes Questionnaire. J Hand Surg. 1998; 23: 575-87.

10. Hudak PL, Amadio PC, Bombardier C, et al. Development of an upper extremity outcome measure: the DASH (Disabilities of the Arm, Shoulder, and Hand). Am J Industr Med. 1996; 29: 602-8.

11. Ware JE, Keller SD, Gandek B, et al. Evaluating translations of health status questionnaires: methods from the IQOLA Project. Int J Technol Assess Health Care. 1995; 11: 525-51.

12. Beaton DE, Bombardier C, Guillemin F, et al. Guidelines for the process of cross-cultural adaptation of self-report measures. Spine. 2000; 25: 3186-91.

13. Leeb B, Sautner J, Andel I, et al. SACRAH: a score for assessment and quantification of chronic rheumatic affections of the hands. Rheumatology. 2003; 42: 1173-8.

14. Monticone M, Ferrante S, Rocca B, et al. Chronic pain acceptance questionnaire: confirmatory factor analysis, reliability, and validity in Italian subjects with chronic low back pain. Spine. 2013; 38: 824-31.

15. Duger T, Yakut E, Oksuz C, et al. Reliability and validity of the Turkish version of the Disabilities of the Arm, Shoulder and Hand (DASH) Questionnaire. Fizyoter Rehab. 2006; 17: 99.

16. Zinbarg R, Yovel I, Revelle W, et al. Estimating generalizability to a universe of indicators that all have one attribute in common: A comparison of estimators for omega. Appl Psychol Measure. 2006; 30: 121-44.

17. Feise RJ, Menke JM. Functional rating index: a new valid and reliable instrument to measure the magnitude of clinical change in spinal conditions. Spine. 2001; 26: 78-87.

18. Marx RG, Menezes A, Horovitz L, et al. A comparison of two time intervals for test-retest reliability of health status instruments. J Clin Epidemiol. 2003; 56: 730-5. 